\title{
Transdermal Absorption of Bupranolol in Rabbit Skin in Vitro and in Vivo
}

\author{
Taro Ogiso, * Tomona Hata, Masahiro Iwaki, and Tadatoshi TANino \\ Faculty of Pharmaceutical Sciences, Kinki University, 3-4-1 Kowakae, Higashi-Osaka, Osaka 577-8502, Japan. \\ Received September 18, 2000; accepted January 29, 2001
}

\begin{abstract}
This study was designed to clarify the percutaneous penetration of bupranolol (BP), a $\beta$-adrenoceptor antagonist, through rabbit skin and to compare the in vitro penetration with the in vivo absorption. BP penetrated across the skin slowly in the absence of enhancers in vitro. Isopropyl myristate and $N$-methyl-2-pyrrolidone enhanced the in vitro penetration, with a 3.6 times higher flux compared with that without enhancers. However, in the in vivo percutaneous absorption, the maximal penetration was obtained with the formulation added $d$ limonene, with a 3.0 times higher area under the concentration-time curve $(A U C)$ than that for the formulation without enhancers. The plasma levels of BP determined, however, were extremely lower than the theoretical plasma steady-state concentrations predicted. The plasma levels of BP after application of these formulations were maintained in the range of $7-22 \mathrm{ng} / \mathrm{ml}$ for $30 \mathrm{~h}$, of which concentrations were above the therapeutically effective concentration $(1.5-4 \mathrm{ng} / \mathrm{ml})$. Therefore, the transdermal systems will offer an efficient drug delivery system for the treatment of angina pectoris and tachycardia.
\end{abstract}

Key words bupranolol skin penetration; in vitro penetration; in vivo absorption; penetration enhancer; rabbit skin

Bupranolol (BP) is a $\beta$-adrenoceptor blocker with a chlorine substituent in the molecule. After oral administration of $200 \mathrm{mg}$ BP to healthy volunteers, the maximum plasma concentration was observed within $1.2 \mathrm{~h}$, but it only reached a level close to the dissociation constant $\left(\mathrm{k}_{1}\right)$ value at beta ${ }_{1}$ and beta $_{2}$-adrenoceptors $(1.5-4 \mathrm{ng} / \mathrm{ml}$ in plasma), and the elimination from plasma was rapid $\left(t_{1 / 2}, 2.0 \mathrm{~h}\right){ }^{1)}$ due to the extensive metabolism. ${ }^{2)}$ It is also shown that BP is subject to extensive first-pass metabolism after oral administration in both humans and animals. ${ }^{2,3}$

The transdermal delivery may offer an attractive possibility for several reasons. The main advantages of the transdermal route is the possibility to continuously deliver drugs with short half-lives and prolonged effects by continuous absorption. However, the amount which can be administered transdermally is quite low. To facilitate the transdermal transport of drugs, various enhancing methods have been tried: iontophoresis, ${ }^{4,5)}$ phonophoresis, ${ }^{6)}$ chemical methods ${ }^{7,8)}$ and absorption enhancers.

There are some reports on the transdermal delivery of BP. Wellstein et al. have shown that steady-state plasma concentrations and the effect of BP could be achieved by a transdermal delivery system applied each day. ${ }^{1}$ Pharmacodynamic effects of transdermal BP have also been reported. ${ }^{9,10)}$ However, penetration characterics of BP have not yet been fully clarified.

In this study we investigated both in vivo and in vitro percutaneous penetration of BP through rabbit skins. The effect of some absorption enhancers on the permeation were also examined in both situations. The correlation between in vivo absorption and in vitro penetration was estimated based on the results obtained.

\section{MATERIALS AND METHODS}

Materials BP was a generous gift of Kaken Pharmaceutical Co., Ltd. (Tokyo, Japan). Carbopol 934, a gel base, was purchased from Kishida Chemical Co., Ltd. (Osaka, Japan). $d$-Limonene, isopropyl myristate (IPM) and $N$-methyl-2pyrrolidone (NMP) were obtained from Aldrich Chemical
Co. (Milwaukee, WI, U.S.A.), Sigma Chemical Co. (St. Louis, MO, U.S.A.) and Nacalai Tesque, Inc. (Kyoto, Japan), respectively. Propranolol (PL) hydrochloride, an internal standard for high performance liquid chromatography (HPLC), was purchased from Ono Pharmaceutical Industry Co. (Osaka, Japan). Other chemicals and solvents used were of reagent grade or HPLC quality.

The free form of BP was prepared from the hydrochloride form by extraction with $n$-hexane at an alkaline $\mathrm{pH}$, washing the extract with water and evaporation of hexane from the extract.

Male Japanese white rabbits, weighing 3.0 to $3.5 \mathrm{~kg}$, were used. The animals had free access to RC4 diet (Oriental Yeast Co., Tokyo, Japan) and water before and during the experiment. They were kept in a breeding room at $24 \pm 1^{\circ} \mathrm{C}$.

Preparation of Gel Ointments and Their Transdermal Systems 1) Gel Ointments: Carbopol 934 was added to distilled water, allowed to swell for $1 \mathrm{~h}$ at room temperature and neutralized with 5\% ammonia water (gel base). BP dissolved in a mixture of ethanol and propylene glycol was mixed with the gel base. Enhancer and lauric acid were also dissolved in the mixture of both solvents. Gentamicin sulfate solution $(10 \mathrm{mg} / \mathrm{ml}$, Sigma Chemical Co.) was added to the gel base. Details of the composition are listed in Table 1.

2) Transdermal System: A transdermal system containing $1.92 \mathrm{~g}$ of gel ointment (BP, $57.6 \mathrm{mg}$ ) and having an ab-

Table 1. Composition of BP Gel Ointments

\begin{tabular}{lccc}
\hline \hline Composition (g) & Rp. 1 & Rp. 2 & Rp. 3 \\
\hline Bupranolol & 3.0 & 3.0 & 3.0 \\
Lauric acid & 2.21 & 2.21 & - \\
Carbopol 934 & 3.0 & 3.0 & 3.0 \\
EtOH/propylene glycol $(2: 1, \mathrm{v} / \mathrm{v})$ & 50.0 & 50.0 & 50.0 \\
$5 \% \mathrm{NH}_{4} \mathrm{OH}$ & q.s. & q.s. & q.s. \\
d-Limonene & - & 5.0 & - \\
Isopropyl myristate & - & - & 5.0 \\
$N$-Methyl-2-pyrrolidone & - & - & 5.0 \\
Gentamicin solution (ml) & 1.0 & 1.0 & 1.0 \\
Purified water ad. & 100.0 & 100.0 & 100.0 \\
\hline
\end{tabular}


sorption area of $16 \mathrm{~cm}^{2}$ was prepared. ${ }^{11)}$

Intravenous (I.V.) Administration BP hydrochloride dissolved in a mixture of dimethylformamide, ethanol, and water $(3: 1: 6, \mathrm{v} / \mathrm{v})$ was administered intravenously at a $4 \mathrm{mg} / \mathrm{kg}$ (BP eq) dose. Blood samples were withdrawn periodically for $10 \mathrm{~h}$ from the ear vein.

In Vitro Percutaneous Penetration Experiments Rabbits were sacrificed by the i.v. injection of chloroform. Skin samples were obtained from the back area of rabbits. The adherent fat and other visceral debris were removed. The dermal side of full-thickness skin was soaked in buffer $(0.85 \%$ $\mathrm{NaCl}-10 \mathrm{~mm}$ phosphate buffer, $\mathrm{pH} 7.4$ ) for $12 \mathrm{~h}$ at $4{ }^{\circ} \mathrm{C}$ to equilibrate the skin. Then $0.25 \mathrm{~g}$ gel ointment was uniformly spread over the stratum corneum of the skin, which was mounted in a Franz diffusion cell (reservoir volume $10.5 \mathrm{ml}$, $1.6 \mathrm{~cm}$ i.d. $O$-ring flange), and occluded with aluminum foil. Gentamicin sulfate solution $(10 \mathrm{mg} / \mathrm{ml})$ was added to the receptor fluid $(0.85 \% \mathrm{NaCl}-10 \mathrm{~mm}$ phosphate buffer, $\mathrm{pH} 7.4)$ at a ratio of $1: 100$. The diffusion cells were thermoregulated with a water jacket at $37^{\circ} \mathrm{C}$ for $52 \mathrm{~h}$. Aliquots $(100 \mu \mathrm{l})$ of receptor fluid were withdrawn periodically. The samples were stored frozen until the time of assay.

In Vivo Percutaneous Absorption Experiments The hair of the back area of each rabbit was carefully removed with an electric clipper $24 \mathrm{~h}$ prior to application of the formulation. The transdermal therapeutic system which was prepared using a corresponding gel ointment was fixed on the shaved back skin with an adhesive and immediately occluded with an adhesive tape. Blood samples were withdrawn from the ear vein of rabbits periodically for $34 \mathrm{~h}$ after dosing. The plasma was separated immediately by centrifugation and stored frozen until the time of assay.

Determination of BP BP in plasma was determined by the method of Winkler and Lemmer ${ }^{12)}$ with modifications. A $200 \mu \mathrm{l}$ plasma was mixed with $150 \mu \mathrm{l}$ methanol containing PL hydrochloride (500 ng/ml, PL eq) and $100 \mu 10.5 \mathrm{~N} \mathrm{NaOH}$. $\mathrm{BP}$ in plasma was extracted by $3.0 \mathrm{ml}$ chloroform. Aliquots of the organic layer $(2.5 \mathrm{ml})$ were evaporated under reduced pressure. Residues were dissolved in $30 \%$ acetonitrile. The solution was filtered through a membrane filter $(0.45 \mu \mathrm{m}$, Chromatodisc 4A, Kurabo, Osaka, Japan). The filtrate was injected onto a reversed-phase Unisil Q CN column (4.6X $250 \mathrm{~mm}$ ), which was part of a Shimadzu liquid chromatograph (model LC-10AT) equipped with an ultraviolet (UV) detector (model SPD-10A). For the determination of BP in in vitro sample solutions, a $50 \mu \mathrm{l}$ aliquot of the sample was added to $150 \mu \mathrm{l}$ methanol containing PL hydrochloride (PL $500 \mathrm{ng} / \mathrm{ml})$. After mixing and centrifuging, the supernatant was filtered through a membrane filter mentioned above, and the filtrate was injected onto a reversed-phase Unisil Q CN column. The mobile phase, $0.1 \%$ phosphoric acid-acetonitrile $(90: 10, \mathrm{v} / \mathrm{v})$, was pumped at a flow rate of $1.0 \mathrm{ml} / \mathrm{min}$ at $35^{\circ} \mathrm{C}$. The detection was $206 \mathrm{~nm}$. The sensitivity of the method was $5 \mathrm{ng} / \mathrm{ml}$ in the plasma and $500 \mathrm{ng} / \mathrm{ml}$ in the sample solution.

Data Analysis The plasma concentration-time data after i.v. administration of $\mathrm{BP}$ were fitted to the following equation:

$$
C_{t}=A e^{-\alpha t}+B e^{-\beta t}
$$

where $C_{t}$ is the drug concentration at time $t$ and $A, \alpha, B$ and $\beta$ are the biexponential equation constants.

The area under the concentration-time curve $(A U C)$ up to the last sampling point was calculated by the trapezoidal method, and the $A U C$ beyond the last observed plasma concentration $\left(C_{\mathrm{n}}\right)$ was extrapolated according to $C_{\mathrm{n}} / \beta$ (or $k_{\mathrm{e}}$ ). The area under the first moment curve $(A U M C)$ and the mean residence time (MRT) were calculated by means of moment analysis. ${ }^{13)}$ The apparent percutaneous absorption rate constant $\left(k_{\mathrm{a}}\right)$ was calculated from the plasma concentrations at initial time periods.

The theoretical plasma steady-state concentrations $\left(C_{\mathrm{ss}}\right)$ was predicted with the following equation:

$$
C_{\mathrm{ss}}=\frac{J_{S} \mathrm{TTS}_{\mathrm{area}}}{C l_{\mathrm{tot}}}
$$

where TTS area $_{\text {is }}$ the surface area of the formulation $\left(16 \mathrm{~cm}^{2}\right)$, $J s$ is the in vitro penetration rate and $C l_{\text {tot }}$ denotes the plasma clearance.

The in vitro percutaneous penetration parameters were calculated from the penetration data using the following equations:

$$
\begin{aligned}
& D=\frac{\delta^{2}}{6 \tau} \\
& J_{S}=\frac{D K_{\mathrm{m}} C_{\mathrm{s}}}{\delta}=K_{\mathrm{p}} C_{\mathrm{s}}
\end{aligned}
$$

where $K_{\mathrm{m}}$ denotes the skin/vehicle partition coefficient, $D$ is the diffusion constant within skin, $\tau$ represents the lag time and $\delta$ is the thickness $(0.002 \mathrm{~cm})$ of the stratum corneum, $K_{\mathrm{p}}$ denotes the permeability coefficient through the stratum corneum, and $C_{\mathrm{s}}$ is the drug concentration in the gel ointment.

The means of all data are presented with their standard deviation (mean \pm S.D.). Statistical analysis was performed using the non-paired Student's $t$-test, and a $p$ value of 0.05 or less was considered to be significant.

\section{RESULTS AND DISCUSSION}

I.V. Administration The plasma concentration-time curves after i.v. administration of BP at a dose of $4.0 \mathrm{mg} / \mathrm{kg}$ are shown in Fig. 1. The plasma concentrations of BP administered declined biexponentially, with a relatively small $t_{1 / 2, \beta}$

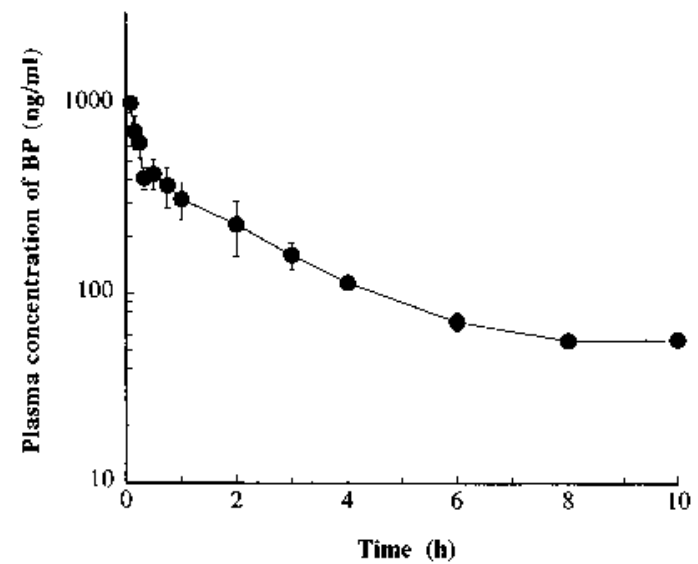

Fig. 1. Plasma Concentration of BP after Single I.V. Administration Each point represents the mean \pm S.D. $(n=3)$. The i.v. dose was $4.0 \mathrm{mg} / \mathrm{kg}$. 
Table 2. Pharmacokinetic Parameters of BP Following Single I.V. Administration

\begin{tabular}{lc}
\hline \hline Parameters & \\
\hline$A(\mathrm{ng} / \mathrm{ml})$ & $1154.49 \pm 246.33$ \\
$\alpha\left(\mathrm{h}^{-1}\right)$ & $8.03 \pm 2.44$ \\
$B(\mathrm{ng} / \mathrm{ml})$ & $444.55 \pm 16.03$ \\
$\beta\left(\mathrm{h}^{-1}\right)$ & $0.33 \pm 0.06$ \\
$t_{1 / 2, \alpha}(\mathrm{h})$ & $0.09 \pm 0.03$ \\
$t_{1 / 2, \beta}(\mathrm{h})$ & $2.17 \pm 0.43$ \\
$k_{12}\left(\mathrm{~h}^{-1}\right)$ & $4.86 \pm 1.84$ \\
$k_{21}\left(\mathrm{~h}^{-1}\right)$ & $2.43 \pm 0.46$ \\
$k_{10}\left(\mathrm{~h}^{-1}\right)$ & $1.07 \pm 0.28$ \\
$A U C(\mathrm{ng} \cdot \mathrm{h} / \mathrm{ml})$ & $2139.17 \pm 659.87$ \\
$A U M C\left(\mathrm{ng} \cdot \mathrm{h}^{2} / \mathrm{ml}\right)$ & $19571.15 \pm 14190.21$ \\
$M R T(\mathrm{~h})$ & $8.23 \pm 4.66$ \\
$C l_{\text {tot }}(1 / \mathrm{h} / \mathrm{kg})$ & $2.01 \pm 0.73$ \\
$V d_{\mathrm{ss}}(1 / \mathrm{kg})$ & $14.47 \pm 4.89$ \\
\hline
\end{tabular}

Each value represents the mean \pm S.D. $(n=3) . k_{12}$ and $k_{21}$ : distribution rate constants. $k_{10}$ : elimination rate constant, $C l_{\text {tot }}$ : total clearance, $V d_{\mathrm{ss}}$ : distribution volume.

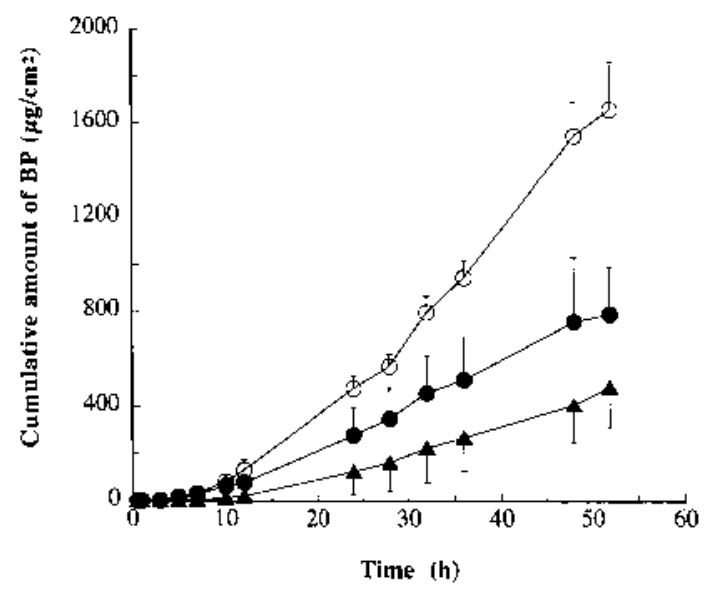

Fig. 2. Penetration Profiles of BP through Rabbit Skin after Application of Gel Ointments

Each point represents the mean \pm S.D. $(n=4-5)$. $\boldsymbol{\Delta}$, Rp. 1 ;, Rp. 2 ; O, Rp. 3.

(2.1 h) and high $C l_{\text {tot }}$ value $(2.01 \mathrm{l} / \mathrm{h} / \mathrm{kg})$. The pharmacokinetic parameters are summarized in Table 2. Although there have been no reports on the i.v. pharmacokinetics of BP in rabbits, our data clarified that the elimination of BP is biexponential, like that of other $\beta$-blockers such as $\mathrm{PL}^{14)}$ and penbutolol. ${ }^{15)}$

In Vitro Skin Penetration In vitro penetration of BP through rabbit skin was estimated in the presence or absence of some penetration enhancers, $d$-limonene or IPM and NMP. The results are shown in Fig. 2 and Table 3. The penetration rate $\left(J_{S}\right)$ of BP from the gel ointment without enhancers was relatively small. When IPM and NMP were added to the ointment, the extensive penetration of BP was observed, with high $J_{S}$ and $K_{\mathrm{p}}$ values. $d$-Limonene also enhanced the penetration, but the enhancement effect was much less than that with IPM plus NMP. IPM is an enhancer and fluidizes the stratum corneum lipids, ${ }^{16)}$ while NMP affects the polar routes through skin. ${ }^{17)}$ Therefore, the cooperation of IPM and NMP might increase both permeabilities of BP via the stratum corneum and the polar routes in vitro.

Since it is shown that the steady-state rate of permeation across the skin is approximately proportional to the solubility of drugs in the stratum corneum, ${ }^{18)}$ IPM and NMP are
Table 3. In Vitro Skin Penetration Parameters of BP through Rabbit Skin

\begin{tabular}{lrrr}
\hline \hline Parameters & \multicolumn{1}{c}{ Rp. 1} & Rp. 2 & \multicolumn{1}{c}{ Rp. 3 } \\
\hline$\tau(\mathrm{h})$ & $14.85 \pm 7.31$ & $8.28 \pm 2.78$ & $14.91 \pm 1.91$ \\
$D\left(10^{-8} \mathrm{~cm}^{2} / \mathrm{h}\right)$ & $6.68 \pm 6.05$ & $8.05 \pm 24.0$ & $4.53 \pm 0.62$ \\
$J_{S}\left(\mu \mathrm{g} / \mathrm{h} \cdot \mathrm{cm}^{2}\right)$ & $12.48 \pm 3.18$ & $18.38 \pm 5.17$ & $45.73 \pm 6.94^{a)}$ \\
$K_{\mathrm{p}}\left(10^{-4} \mathrm{~cm} / \mathrm{h}\right)$ & $4.16 \pm 1.06$ & $6.13 \pm 1.72$ & $15.24 \pm 2.31^{a)}$ \\
\hline
\end{tabular}

$J_{s}$ : penetration rate, $K_{\mathrm{p}}$ : permeability coefficient through skin, $\tau$ : lag time, $D$ : diffusion constant with skin. Each value represents the mean \pm S.D. $(n=4-5)$. a) $p<0.05$ compared with Rp. 1 and Rp. 2.

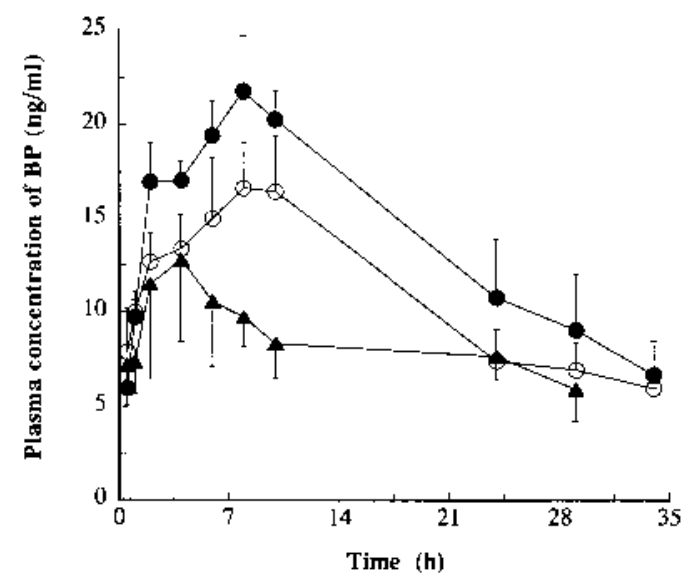

Fig. 3. Plasma Concentrations of BP after Single Percutaneous Administration of BP Formulations

Each point represents the mean \pm S.D. $(n=3)$. Applied formulation was $1.92 \mathrm{~g} / 16 \mathrm{~cm}^{2}$. $\boldsymbol{\Delta}$, Rp. 1 formulation; $\bullet$, Rp. 2 formulation; $\bigcirc$, Rp. 3 formulation.

Table 4. Pharmacokinetic Parameters of BP Following Single Percutaneous Administration

\begin{tabular}{lccc}
\hline \hline \multicolumn{1}{c}{ Parameters } & Rp. 1 & Rp. 2 & Rp. 3 \\
\hline$k_{\mathrm{a}}\left(\mathrm{h}^{-1}\right)$ & $0.348 \pm 0.126$ & $0.705 \pm 0.104^{a)}$ & $0.470 \pm 0.103$ \\
$A U C_{0-\infty}(\mathrm{ng} \cdot \mathrm{h} / \mathrm{ml})$ & $210.57 \pm 73.27$ & $626.96 \pm 57.54^{a)}$ & $471.92 \pm 34.39^{a)}$ \\
$A U M C_{0-\infty}\left(\mathrm{ng} \cdot \mathrm{h}^{2} / \mathrm{ml}\right)$ & $3210.63 \pm 2798.01$ & $15040.72 \pm 1233.69$ & $\left.14431.99 \pm 1855.21^{a}\right)$ \\
$M R T(\mathrm{~h})$ & $13.49 \pm 7.57$ & $24.06 \pm 2.00$ & $30.86 \pm 6.08$ \\
$F(\%)$ & $2.05 \pm 0.49$ & $6.11 \pm 0.62^{a)}$ & $4.60 \pm 0.80^{a)}$ \\
\hline
\end{tabular}

Each value represents the mean \pm S.D. $(n=3) . F$ : bioavailability (\%). a) $p<0.05$ compared with Rp. 1.

thought to enhance the solubility of BP in the stratum corneum to a large extent.

In Vivo Percutaneous Absorption In comparison with the results obtained by the in vitro penetration experiment, the in vivo absorption of BP was examined. The plasma BP concentrations during a single percutaneous application of the formulations are shown in Fig. 3. The plasma levels of BP after application of the formulation without enhancers were relatively low $\left(C_{\max }, 12.8 \mathrm{ng} / \mathrm{ml}\right)$, while the plasma levels after application of the formulation with $d$-limonene (Rp. 2) gradually increased and reached a peak plasma concentration of $21.8 \pm 2.92 \mathrm{ng} / \mathrm{ml}$ at $8 \mathrm{~h}$ postadministration. The $A U C_{0-\infty}$ calculated for the Rp. 2 formulation was $627.0 \pm 57.54 \mathrm{ng} \cdot \mathrm{h} / \mathrm{ml}$ and was significantly larger than that $(210.57 \pm 73.27 \mathrm{ng} \cdot \mathrm{h} / \mathrm{ml})$ for the formulation without enhancers $(p<0.01)$ (Table 4$)$. The $A U C_{0-\infty}$ values were approximately proportional to the $k_{\mathrm{a}}$ values. As a result, the enhancement ratio of percutaneous absorption by enhancers was mostly related to the plasma concentrations in the in vivo 
Table 5. Comparison of in Vitro Penetration Data with in Vivo Percutaneous Absorption Parameters of BP

\begin{tabular}{|c|c|c|c|c|c|c|}
\hline \multirow{2}{*}{ Formulation } & \multicolumn{2}{|c|}{ In vitro } & \multicolumn{3}{|c|}{ In vivo } & \multirow{2}{*}{$\begin{array}{l}\left.\text { Predicted } C_{\mathrm{ss}}{ }^{b}\right) \\
\quad(\mathrm{ng} / \mathrm{ml})\end{array}$} \\
\hline & $J_{s}\left(\mu \mathrm{g} / \mathrm{h} \cdot \mathrm{cm}^{2}\right)$ & Ratio $^{a)}$ & $A U C_{0-\infty}(\mathrm{ng} \cdot \mathrm{h} / \mathrm{ml})$ & Ratio $^{a)}$ & $C_{\max }(\mathrm{ng} / \mathrm{ml})$ & \\
\hline 1 & 12.48 & 1.00 & 210.57 & 1.00 & 12.81 & 102.21 \\
\hline 2 & 18.38 & 1.43 & 626.96 & 2.98 & 21.78 & 146.31 \\
\hline 3 & 45.73 & 3.56 & 471.92 & 2.24 & 16.68 & 364.02 \\
\hline
\end{tabular}

a) The value for formulation 2 or $3 /$ the value for formulation $1 . \quad b) C_{\mathrm{ss}}=J s \cdot \mathrm{TTS}_{\mathrm{area}} / C l_{\mathrm{tot}}$.

absorption. The reason $d$-limonene exerted the most enhancing effect in vivo may be that the enhancer acts by modifying intercellular lipids, fluidizing the lipids, ${ }^{16,19)}$ and removing the intercellular lipids ${ }^{16)}$ to increase diffusivity of lipophilic $\mathrm{BP}$ in the stratum corneum, resulting in the rapid absorption of the drug in the viable epidermis. However, in an in vitro situation, this enhancer could not fully enhance the drug penetration through the skin. The enhancement effect in the dermis would be insufficient, probably due to less distribution of the enhancer into the tissue.

The plasma BP concentrations after application of three formulations were compared with the $C_{\mathrm{ss}}$ values, predicted with the $J S$ and $C l_{\text {tot }}$. A clear correlation was not observed between the plasma concentrations and $C_{\mathrm{ss}}$ values (Table 5). In addition, the predicted $C_{\mathrm{ss}}$ values for all formulations used were much higher than the plasma levels obtained. The low plasma levels might mainly be due to the extensive metabolism of BP in the systemic circulation after percutaneous absorption ( $28 \%$ of blood flow pass through the liver). BP undergoes extensive first-pass metabolism in man and animals, less than $10 \%$ being excreted in the urine unchanged. ${ }^{2)}$ It thus appears that the systemic plasma clearance of BP might be dose-dependent and might decrease with increasing doses in the rats. Therefore, BP at lower plasma concentrations, such as in percutaneous absorption, would show a large systemic clearance. In addition, the low plasma levels in the in vivo percutaneous absorption might partly be related to the binding to tissue components during the absorption process. $\mathrm{BP}$ is shown to be a drug high in protein binding (plasma protein binding, $80-90 \%){ }^{1)}$ It is found that ten drugs containing propranolol and clonidine were significantly bound to the epidermis and corium of human skin. ${ }^{20)}$

The therapeutically effective concentrations of BP are thought to be $1.5-4 \mathrm{ng} / \mathrm{ml}$ in human plasma. ${ }^{1)}$ The plasma levels of BP after application of these formulations were maintained in the range of $7-22 \mathrm{ng} / \mathrm{ml}$ for about $30 \mathrm{~h}$. As a result, these transdermal systems will be able to be used as efficient drug delivery systems for the treatment of angina pectoris and tachycardia.

In conclusion, BP could easily penetrate through rabbit skin in the presence of some enhancers. The in vivo percutaneous absorption of the drug was enhanced by application of the formulation with $d$-limonene to much extent. However, a good correlation was not observed between the plasma levels measured and the $C_{\mathrm{ss}}$ values predicted in this study. The transdermal systems have the potential to be an efficient drug delivery system for the treatment of angina pectoris and tachycardia.

\section{REFERENCES}

1) Wellstein A., Kuppers H., Pitschner H. F., Palm D., Eur. J. Clin. Pharmacol., 31, 419-422 (1986).

2) Waller A. R., Chasseaud L. F., Bonn R., Taylor T., Darragh A., Girkin R., Down W. H., Doyle E., Drug Metab. Dispos., 10, 51-54 (1982).

3) Kagiwada K., Kamasuka T., Maeda T., Asami Y., Shoji S., Oyo Yakuri, 7, 317-332 (1973).

4) Sanderson J. E., Caldwell R. W., Hasio J., Dixon R., Tuttle R. R., J. Pharm. Sci., 76, 215-218 (1987)

5) Siddiqui O., Sun Y., Liu J.-C., Chien Y. W., J. Pharm. Sci., 76, 341345 (1987).

6) Meidan V. M., Docker M., Walmsley A. D., Irwin W. J., Pharm. Res., 15, 85-92 (1998).

7) Hadgraft J., Walters K. A., Wotton P. K., Int. J. Pharm., 32, 257-263 (1986).

8) Ogiso T., Shintani M., J. Pharm. Sci., 79, 1065-1071 (1990).

9) Kemken J., Ziegler A., Muller B. W., Meth. Find. Exp. Clin. Pharmacol., 13, 361-365 (1991).

10) Jeck T., Edmonds D., Mengden T., Schubert M., Renz I., Weisser B., Vetter W., Int. J. Clin. Pharm. Res., XII, 139-147 (1992).

11) Ogiso T., Iwaki M., Yoneda I., Horinouchi M., Tsujimoto C., Chem. Pharm. Bull., 39, 449—453 (1991).

12) Winkler H., Lemmer B., J. Chromatogr., 309, 193-197 (1984).

13) Gibaldi M., Perrier D. (eds.), "Pharmacokinetics," 2nd ed., Marcel Dekker, New York, 1982, pp. 84-111 and 409-417.

14) Ogiso T., Iwaki M., Kashitani Y., Yamashita K., Chem. Pharm. Bull., 39, 2657-2661 (1991).

15) Heel R. C., Brogden R. N., Speight T. M., Avery G. S., Drugs, 22, $1-$ 25 (1981).

16) Ogiso T., Iwaki M., Paku T., J. Pharm. Sci., 84, 482-488 (1995).

17) Southwell D., Barry B. W., J. Invest. Dermatol., 80, 507-514 (1983).

18) Tojo K., Chiang C. C., Chien Y. W., J. Pharm. Sci., 76, 123-126 (1987).

19) Williams A. C., Barry B. W., Pharm. Res., 8, 17-34 (1991).

20) Walter K., Kurz H., J. Pharm. Pharmacol., 40, 689-693 (1988). 